obliged to adopt a stooping attitude when walking about. She has not menstruated since her confinement. There was no pain when the bowels acted, but there was some constipa. tion; no pain in passing urine. Father and mother living, and in good health. On physical examination, the abdomen was found uniformly distended, the superficial abdominal veins prominent, and the umbilicus displaced slightly to the left of the middle line. On percussion, dulness varied with the position of the patient, but was found to be persistent to the left and slightly below the umbilicus over an area about four inches in diameter. The feet were some what oedematous. Nothing abnormal in the lungs or heart was detected. The measurements of the abdomen were : xiphoid cartilage to symphysis pubis, 14 in.; xiphoid cartilage to umbilicus, 71 in.; umbilicus to symphysis, 7 in.; umbilicus to right anterior superior iliac spine, 8 in.; umbilicus to left anterior superior spine, 8 in.; girth of abdomen at umbilicus, 36 in.; middle line behind to umbilicus (left), 17/ in.; (right), 183in. The temperature on admission was $100^{\circ}$, and subsequently went up each night to $101^{\circ}$ or $102^{\circ}$ as a rule. The diagnosis was tubercular peritonitis, and Dr. Underhill decided to perform abdominal section.

On May 14th a three-inch long incision was made in the middle line below the umbilicus, and a large encysted fluid aceumulation found, sixteen pints of yellow fluid being drawn off. Intestines covered with yellow and grey tubercles. The abdominal cavity was thoroughly irrigated with a hot dilute solution of creolin, the wound closed sutured, and dressed antiseptically. The patient was put to bed and ordered enemata of brandy, beef-tea, and milk every three hours, and two teaspoonfuls of brandy by the mouth every hour. An injection of morphia subcutaneously was also given.

May 15th. - She has been sick several times. Pulse 120; a good deal of pain occasionally; temperature $99^{\circ}$. A quarter of a grain of morphia was given subcutaneously.16th : Tongue rather dry. No pain. Pulse 120. Says she feels better. Temperature $100^{\circ}$. Enemata continued.17th : Given a little food by the mouth. Pulse 100, and improved in character. Tongue not so dry. No pain. Two sutures removed.-22nd: Patient much better. All the sutures removed. No pain. Enemata discontinued. Allowed chicken. Recovery from this time was only interrupted by a mild attack of urticaria, and the patient was discharged on June 12th quite well. The wound healed by first intention.

Condition on discharge: Linear cicatrix ; no abdominal distension ; girth at umbilicus 28 in. ; abdomen quite soft on palpation; bowels acting regularly; no pain. The patient rapidly gained flesh and strength after the operation. She was seen on July 10th, and was then perfectly well.

\section{MASSACHUSETTS GENERAL HOSPITAL, BOSTON, U.S.A.}

A CASE OF SARCOMA OF THE TONSIL REMOVED BY EXTERNAL INCISION ; RECOVERY.

(Under the care of Dr. JoHn Homans.)

INSTANCES of the removal of a tonsil the seat of a sarcomatous growth are not common, and we present our readers with the following description of a case, although some notes of it have already appeared in the Boston Medical and Surgical Journal. In cases where from the small amount of disease it is possible to remove the gland from within the mouth without external incision, that method is adopted. The desire, however, to make certain that all the growth has been removed may induce a surgeon to combine that method with external incision, although it may be possible that removal could be effected without. Czerny and Mikulicz combined section of the lower jaw with the external incision, the latter even resecting the ascending ramus of the bone. Both recommended the performance of a preliminary tracheotomy. By these methods the tonsillar region is certainly exposed in a complete manner, and the arrest of any hremorrhage during the operation or afterwards made more easy.

Mrs. H. L- aged fifty-nine, entered the Massachusetts General Hospital on May 30th, 1890. About eighteen months before entrance she had noticed swelling and ulceration of the right tonsil, which subsided under treatment. $A$ few months later the swelling and ulceration again returned and again disappeared. In February, 1890, the tonsil again increased in size, and, as she says, "pressed farther into the throat, and she had a nervous feeling extending over the gums and jaw." Thinking this trouble might come from the teeth, she had them all removed, a proceeding which much facilitated the subsequent operation. She had no real difficulty in swallowing, but the passage of food through the pharynx was uncomfortable. In the outpatient department for diseases of the throat, on May 20th, Dr. Langmaid cut off half the tonsil with a tonsillitome, and sent the part removed to Dr. Whitney, who reported as follows: "An irregularly lobulated growth, homogeneous and medullary-looking on the section surface. Microscopic examination showed a structure of relatively large round cells, with fine fibrillated intercellular substance replacing the normal tonsil structure. In places there were relatively dense bands of fibrous tissue traversing the growth irregularly. The diagnosis is a round-celled sarcoma." The growth sonn reappeared, and Dr. Langmaid sent the patient into the house for more radical treatment. The right tonsil was now enlarged to about twice the size of the left; it was not inflamed. Projecting from its centre was a soft red mass of about the size and colour of a wild strawberry, and shaped like a pine-apple.

June $6 \mathrm{th}, 1890$. - An incision was made two inches and a half long from the right side of the hyoid bone to the mastoid process. The fasciæ were divided one after another, the edge of the parotid was pushed upward, and the sub. maxillary gland with the tendon of the digastric muscle downward. With the point of a director the constrictor of the pharynx and the nucous membrane in front of the tonsil were torn through. Scissors were used in the mouth to divide the pillars of the palate and the mucous membrane around the tonsil. Forceps were then introduced through the wound in the neck and the loosened tonsil pulled outwards, while its attachments, which were on the stretch, were divided by scissors introduced through the mouth. Only two small vessels required ligatures, a superficial branch of the facial and a small artery in the soft palate. The split in the pharynx, which was about two inches and a half long, was united by a continuous silk suture, and a quill drainage-tube was introduced through the external wound. Dry iodoform gauze with compression was applied over the wound in the neck. The complete absence of fat and of teeth in a thin, but tongh and wiry, subject made the operation extremely simple.

7th.-Reports a comfortable night. She had a mouthwash of permanganate of potash, and was fed solely by nutrient enemata every four hours.

8th.-Considerable swelling in the right pharynx, but no great discomfort.

9 th. -Took three ounces of milk every two hours, and swallowed well. The swelling in the pharynx had much diminished.

10th.-External wound united by first intention; little swelling ; drainage-tube removed.

15th.-Patient up and dressed.

20th. - The stitch in the pharynx was easily removed, and the patient was discharged well.

Remarks by Dr. HoMANS.-Perhaps this operation ought to be called "removal of the tonsil by the combined method of external and internal incision." In 1869, Dr. David W. Cheever of Boston, Professor of Surgery in Harvard College, removed a malignant tumour of the tonsil by cutting down on it from outside the neck and opening the pharynx. So far as he could then learn, the operation was original. Subsequently several treatises on Surgery, such as Bryant's "Sarcoma of the Tonsil," Gross's, and others, sustained his belief that the operation had not been performed before. Dr. Cheever found later that Dr. Hueter states in the "Jahresbericht der gesammten Medicin" for 1869, that he saw von Langenbeck operate externally ard by sawing the jaw in 1865, and that he himself performed a similar operation -in the same year. Both were cases of sarcoma. Langenbeck's recovered; Hueter's died. Nine years later (in 1878) Dr. Cheever operated again. In 1886 Dr. M. H. Richardson operated at the Massachusetts General Hospital successfully by external incision. The growth was a roundcelled sarcoma. The patient recovered rapidly, and has remained well ever since. This case is reported at length in the Boston Medical and Surgical Journal of Feb. 23rd, 1888. From what has been written on this subject it is evident that the prognosis of cases of removal of the tonsil is much mure favourable for sarcoma than for cancer. Dr. 
Richardson's case and my own were cases of sarcoma, and in neither of them has there as yet been any recurrence Dr. Richardson's patient has been well for four and a half years, and may be considered cured, but only a few months have elapsed since the operation in the present case. Mr. Butlin gives twenty-three cases of removal of tumours of the tonsil ; of these, ten were operated on by external incision, and thirteen from within the moutb; two of the former proved fatal, and one of the latter. Richardson's case and my own make the number twenty-five-twelve by external incision, and thirteen from within the mouth. One case (Mr. Barker's, quoted by Mr. Butlin) was well a year after the operation. One by Dr. Gorecki (quoted by the same author) was alive and well two years later. One by Mr. Butlin himself was well four months after operation. Dr. Richardson's case was well four and a half years after operation, and mine showed not the slightest tendency to return after five months. All these were cases of sarcoma; the other twenty cases-mostly, I presume, cancer-are all dead. So far as I know, there is not a single case of cure of cancer of the tonsil by operation. I think that Mr. Butlin's conclusion, that "removal of the disease through an external incision (pharyngotomy) has hitherto proved a dangerous proceeding, and has not yielded as good results as operation through the open mouth," should be qualified, for of these five recoveries two were cases of external incision, and, as the whole number is only five, there must be three of one kind and two of the other. I am, however, free to say that my patient might perfectly well have been operated upon through the mouth, but I chose the external method because I thought I could get more room, control hæmorrhage easier, and remove a healthy margin with more boldness. In conclusion, I desire to express my thanks to Mr. Butlin for the article he has written on the tonsil, as well as the obligations I am under to him for what I have learned from his work on "The Operative Surgery of Malignant Disease," one of the most thoroughly satisfactory books that well-applied observation has ever given us.

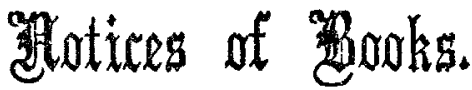

Outlines of Medical Treatment. By Samuen Fenwick, M.D., F.R.C.S., Physician to the London Hospital; and W. SoltaU Fenwick, M.D., B.S. Lond., M.D. Strasburg. Third Edition. - This hook is well known to the profession, and its third edition calls for little notice from us. In the teeming medical literature of the day there is good room for such a book as this, dealing as it does mainly with treatment, and doing so, moreover, in a careful and practical way. This edition gives an excellent account of the latest improvements and advances in treatment-notably, of the treatment of pyrexia by the cold bath, and by means of Dr. Fenwick's own device of the ice cradle. Another novel and interesting feature of the book is a short account at the end of each chapter of the treatment of a disease by the French, German, and American methods. The list of prescriptions has been enlarged, and a chapter on Diet and Regimen has been added. Each chapter is preceded by sound general observations on the points to be kept in view on the given disease as to the nature, cause, and prognosis of the case. It cannot fail to be most useful on the table or in the carriage of every busy practitioner. There is, however, room for a chapter on the medical uses of electricity in its different forms. Occasionally, but very seldom, the treatment recommended is a little antiquated or open to criticism. The chapter on Delirium still smacks too much of the fear of discontinuing the alcohol which has produced the disease, and of faith in opium or morphia. It makes no allusion to the invaluable paper of Dr. George W. Balfour, ${ }^{1}$ on the Use of Chloral, and the necessity for stopping the drink in this disease, which constitutes one of the most valuable contributions to practical therapeutics.

1 THe Laxcer, vol. i. 1879 p. 749
Examen Quimico y Bucteriológico de lus Aquas Potables. Por A. E. Salazar y C. NEwman. Londres: Burns \& Oates. 1891.-.This work on the chemical and bacteriologi. cal examination of potable waters is founded on a systematic series of examinations of different waters carried ont in 1887-8 in the laboratory of the Naval School of Valparaiso, and is intended to serve especially as a guide to chemists and medical men in Chili who have occasion to report upon the suitability of waters for drinking purposes. It is exceedingly well got up-both the typography and engravings, which appear to have been entrusted to an English printer, being excellent. There is, too, in addition to valuable descriptive acconnts of chemical and bacterio. logical processes, an important chapter by Dr. Rafael Blaschard of Paris on animal parasites introduced into the system by means of drinking water. Being written in Spanish, it will doubtless prove a valuable addition to the medical literature of the Peninsula and Spanish America, which is by no means replete with good bacteriological works.

The Pharmacopaias of the London Hospitals. By PETER Souire. Revised by P. W. SuUtre and A. H. SQUIre. Sixth Edition. J. \& A. Churchill. 1891.-A considerable amount of care has obviously been expended upon this useful compilation. Since there is nothing finite in prescrip. tions, and since the Pharmacopoias of the different hospitals are frequently undergoing revision, the editors of this little book have constantly to be on the alert. Since the last issue in 1885 more uban half of the hospitals have passed their Pharmacopoeias under review, and yet amongst the addenda the Pharmacopoia of one hospital is to be found "with alterations and additions from manuseript." The increase in the space now required by the formula sufficiently indicates that the different hospital authorities do not desire to simplify or reduce the number of compound drugs in accordance with the wish expressed in 1863, when the first edition of this book was issued.

The Mcdical Practitioner's Cash-book. Designed by Dr. C. R. Illingworth, Clayton-le-Moors. Manufactured and sold by James Broadley, "Gutenberg" Works, near Accrington.-If we may judge from a specimen page, this fresh addition to professional stationery ought to commend itself to medical men, especially to those engaged in general practice, as much from its simplicity in arrangement as from its comprehensiveness. Every sheet is ruled in headed columns to contain a full statement of income, expenses, and resulting balance for one month, one side being devoted to amounts received, the other to those expended. Thus the financial result for each month can be seen at a glance, and the trouble required in noting is merely nominal. By a simple arrangement of marks, the permissible deductions from income-tax can be stated in order on the expense page. It has often been said that medical practitioners are bad men of business, and we cannot either doubt the assertion or marvel that it should often prove to be true. Without much method and economy of time an opposite condition is altogether incom. patible with the constant work, frequent worries, and innumerable interruptions of a doctor's life. The sheet which lies before us is a simple and ingenious device for ensuring the needed method. A reduction of the present cost (27s. $6 d$. for 200 folios) would probably be found remunerative.

CRHMATION IN GERIIANY. - The practice of crema tion is on the increase in Germany. In addition to the crematorium which has been in operation at Gotha since 1877 , and where from five to six hundred bodies are now cremated every year, a new establishment of the same kind was consecrated at Ohledorf last week. Another crematory will be opened in October at Carleruhe, making the third in Germany. 